\title{
Are "Internet + " tactics the key to poverty alleviation in China's rural ethnic minority areas? Empirical evidence from Sichuan Province
}

\author{
Xiang Yin ${ }^{1}$, Zhiyi Meng ${ }^{2^{*}}\left(\mathbb{D}\right.$, Xin $\mathrm{Yi}^{3}$, Yong Wang ${ }^{4}$ and Xia Hua ${ }^{4}$
}

\author{
${ }^{*}$ Correspondence: \\ zhiyimeng@scu.edu.cn \\ ${ }^{2}$ School of Business, Sichuan \\ University, Chengdu 611130, \\ People's Republic of China \\ Full list of author information \\ is available at the end of the \\ article
}

\begin{abstract}
China has made great efforts to alleviate poverty in rural ethnic minority areas and targeted achieving the poverty-alleviation task by the end of 2020. Aba, Ganzi, and Liangshan, three of the poorest ethnic prefectures in Sichuan Province, Southwest China, have all implemented "Internet+" tactics since 2013, which have had the positive effect of increasing family revenues by improving communication infrastructure and encouraging the large-scale use of e-commerce. This paper aims to comprehensively investigate whether "Internet+" tactics play a key role in poverty alleviation in Sichuan's rural ethnic minority areas and to propose further measures to enhance the efficiency of e-commerce practice. To this end, we conduct an analysis using the framework of classic growth theory and use panel data from 2000 to 2018 to examine the relationship between Communication Infrastructure Investment (CII) and a set of poverty-alleviation indicators, including local GDP growth rate (LGGR), local government revenue (LGR), and per-capita income of residents (PCIR). The results indicate that strengthening CII improves the PCIR and local economic growth, playing a key role in poverty alleviation. However, the stimulation of CII on LGGR and LGR wanes as time passes. More financial and technical actions will be needed to improve the efficiency and quality of current strategies for sustainable development in those areas.
\end{abstract}

Keywords: Poverty alleviation,"Internet+"Tactics, Rural ethnic minority areas, Empirical analysis

\section{Introduction}

China has attached great importance to poverty alleviation in recent years (Wang et al. 2019). The Internet has been deeply integrated into traditional industries and widely used in poverty alleviation. Rosensten-Rodan (1943) asserted that infrastructure construction had played a decisive role in industrialization and stimulating economic growth. Adopting this notion, China's central and municipal governments have introduced the "Internet+" tactics to improve the production efficiency and increase local residents' income in poverty-stricken regions (Gong 2018).

Aba, Ganzi, and Liangshan are ethnic minority prefectures within Sichuan Province and among the most economically laggard regions in Southwest China (Yan and

(c) The Author(s), 2021. Open Access This article is licensed under a Creative Commons Attribution 40 International License, which permits use, sharing, adaptation, distribution and reproduction in any medium or format, as long as you give appropriate credit to the original author(s) and the source, provide a link to the Creative Commons licence, and indicate if changes were made. The images or other third party material in this article are included in the article's Creative Commons licence, unless indicated otherwise in a credit line to the material. If material is not included in the article's Creative Commons licence and your intended use is not permitted by statutory regulation or exceeds the permitted use, you will need to obtain permission directly from the copyright holder. To view a copy of this licence, visit http:// creativecommons.org/licenses/by/4.0/. 


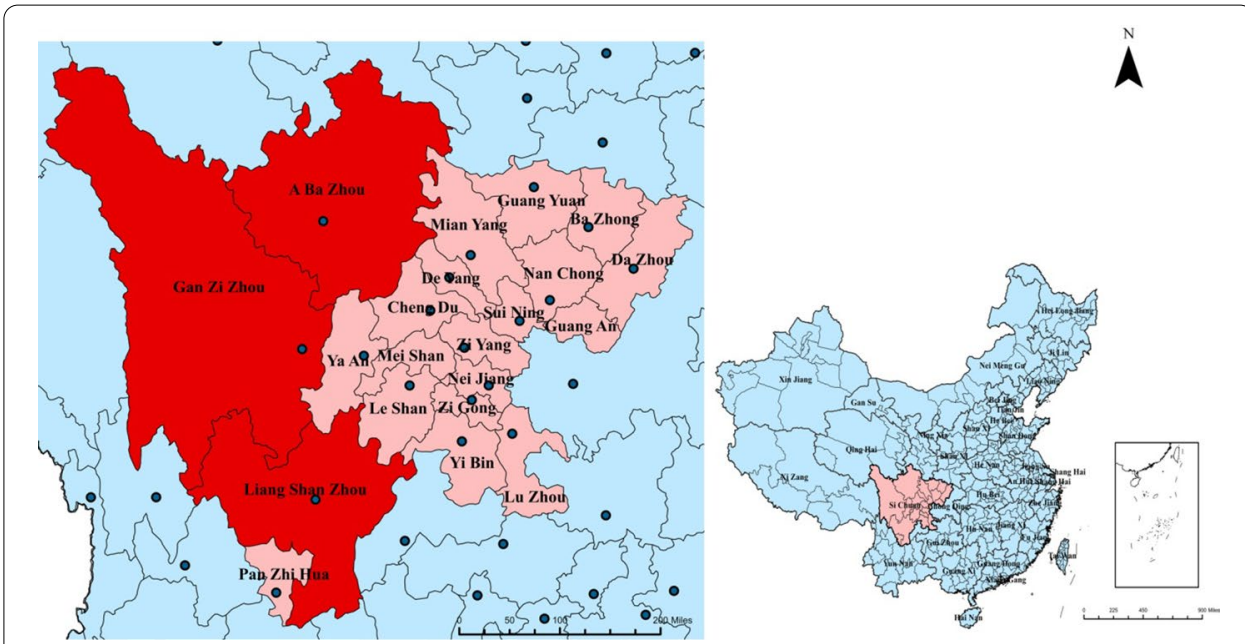

Fig. 1 Location of Aba, Ganzi, and Liangshan Prefectures in Sichuan Province

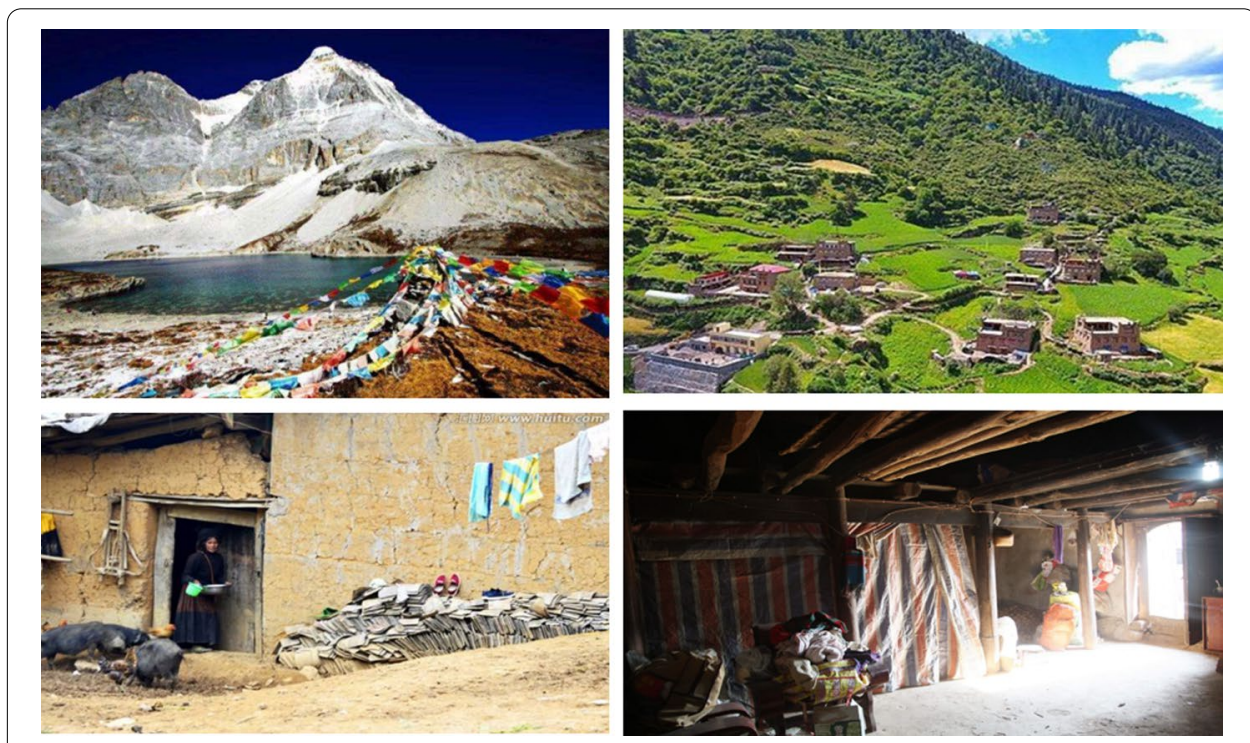

Fig. 2 Beautiful scenery and deep poverty coexist in Aba, Ganzi, and Liangshan. Date source: http://www. dili360.com/article/p5350c3d8a470763.htm;

Qian 2004). Figures 1 and 2 illustrate the general environment and living conditions of the locals. With the aid of the "Internet+" tactics and the communication infrastructure investment (CII), many villagers in ethnic minority areas in Sichuan have started to use e-business platforms such as Taobao and Jingdong to sell agricultural products in recent years. The Internet has played a key role and has lifted many local families out of poverty. Based on the substantial innovative experiences of Hongyuan County in Aba, Jinyang County in Liangshan, and Derong County in Ganzi, the local governments have attempted to build a "co-operative + e-business + Internet media" sales system that integrates local agricultural products, e-business channels, and an Internet media matrix. This new poverty alleviation ecology marks a transition from 
a treat-the-symptom strategy of poverty alleviation to a cure-the-disease one in the poverty-stricken ethnic minority areas of Sichuan Province.

In the existing literature, the relationship between the information technology industry and productivity growth is not well addressed. At the end of the 1980s, Robert Solow noted that the United States had made large-scale investments in information technology, but this investment did not translate into economic productivity. He found that computers were everywhere, but they had never been reflected in productivity. (Solow 1987). This is the famous "Solow Paradox" or "Productivity Paradox". In the mid-1990s, the "new economy" boomed in the US, and the total factor productivity of the non-agricultural sector substantially improved. The role of information technology in promoting economic efficiency had been generally recognized. However, the "Solow Paradox" seems nonexistent in reality. At the beginning of the twenty-first century, as the Internet bubble burst and the US economy was shaken, people began to reexamine the role of information technology and the "productivity paradox". The paradox also manifestated in China. On the one hand, the Internet economy was extremely prosperous, and the e-commerce sales had been hitting ever-increasing records; on the other hand, the total factor productivity of deeply impoverished areas had barely changed. While many suppliers failed to make a smooth transition to the Internet market, fake goods and lowquality copycats took advantage of the fledgling market to rake in huge profits and dealt a fatal blow to many brands with an established reputation. In this light, we raise the question: Can "Internet+" tactics can really work as expected in deeply impoverished areas?

To answer this question, we investigate the relationship between the "Internet+" tactics and rural economic growth. This paper is organized as follows. Section 1 discusses the "Internet+" tactics and the household poverty-alleviation initiative. This section also furnishes a literature review of related theories and models. Section 2 builds on the empirical model, defines indexes, and explains why they are appropriate in this context for the testing of the relevant relationship. Section 3 describes the data. Section 4 details the empirical analysis and discusses the results. The last section summarizes the main findings and provides policy suggestions.

\section{Literature review}

Debates about poverty alleviation are unavoidably intertwined with the trade-off between efficiency and equity, as are the venues suggested from different perspectives on how such alleviation might be obtained (Fosu 2017; Béné et al. 2016; Page and Shimeles 2015).

Some scholars have focused on poverty alleviation from the perspective of corporate social responsibility (CSR). While Kolk (2016) focused on the social responsibility of international businesses with an emphasis on ethics and sustainable development, Zaefarian et al. (2015) conceptualized a market-based approach of poverty alleviation from a corporate perspective. Similarly, Lund et al. (2016) studied the relationship between industrial clusters and corporate social responsibility (CSR) in developing countries to reach the key lessons learned from empirical studies of CSR initiatives. Namely, effective CSR poverty-alleviation strategies are those that aim to improve environmental management and work conditions and reduce poverty in local industrial districts. 
Research with a tilt toward efficiency has shown increasing interest in the role that technology, particularly Internet technology, has played to reduce poverty and strike a better economic balance. Again, the caveat is that poverty alleviation without a welldefined venue and scope will be counterproductive (Copestake et al. 2005). Acemoglu et al. (2014) found that the productivity growth of information technology-intensive industries have slowed since the late 1990s, and the decline in productivity is inconsistent with the view that informatization is the driver of the productivity revolution. In the manufacturing sector the "Solow Paradox" still exists (Acemoglu et al. 2014).

Many researchers have found that information technology can enhance productivity. Lin et al. (2015) found that the development of Internet finance contributes to poverty alleviation in poor areas. Similarly, Chandio et al. (2018) documented that agricultural credit is an essential element of agricultural growth in the developing countries. Olayungbo and Quadri (2019) found that the remittances also contribute to poverty reduction especially through their direct effects.

In the same vein, the typical business model of "Internet+" is the "platform economy," which eases the "friction" in economic transactions and internalizes the externalities in economic transactions, to improve the efficiency of economic operations (Zhu and Chen 2018). Furthermore, the "Internet+" encourages enterprises to acquire and absorb external knowledge with higher efficiency and lower cost, accurately control market demand trends, improve transaction efficiency among innovation entities, and reduce the external transaction costs of enterprises (Zheng et al. 2019). Kennedy and Guzmán (2016) used the tourism and agricultural product processing industry, two sectors closely related to poverty alleviation in rural areas, to show that these industries, characterized by long-term low-efficiency, have greatly improved production efficiency through network technology.

In addition, the remarkable growth of e-commerce has redefined various industries worldwide in recent years (Li 2018; Vakulenko et al. 2019). Social innovation enabled by e-commerce is becoming increasingly notable as a means of reducing poverty in developing countries but has not been studied sufficiently by the IS community (Cui et al. 2017). China's successful experience with e-commerce has had a positive effect on transforming the consumer-goods sectors of the economy and motivating economic reform. Internet technology not only solves the problem of information asymmetry in poverty-stricken areas but also provides advanced technology and cutting-edge perspectives for individuals in remote and impoverished mountainous areas $(\mathrm{Li}$ et al. 2019). As the e-commerce platform facilitates the entry of agricultural products and industrial products into the market and the participation of all stakeholders, consequently, a diversified and open ecosystem is created, and innovation and entrepreneurship are achieved through shared economic models such as crowd-funding and mass creation, and the Internet+tactics such as "Internet+Tourism", "Internet+Medical", "Internet+Agriculture" and "Internet+Finance" (Shen et al. 2020).

However, some scholars have pointed out that, given the rapid development of e-commerce, academic research and management policies in this area are still rare and immature. The influence of e-commerce on regional economies may vary because of the difference in their industrial bases. Tang and Zhu (2020) pointed out in their research that the informality caused by the development of Taobao village not only makes rural 
governance more difficult, but also undermines the operation of leading enterprises. It is worth noting that the areas they studied were China's coastal areas, which developed early after China adopted the reform and opened-up policies, and have much better industrial infrastructures than western inland areas. In these regions, the villages with better e-commerce development are precisely those that are well known for their family businesses. However, the rampant development of e-commerce has increased the cost of factors that traditional family businesses rely on, such as land rents and labor costs. The studies also found that the government's attitude towards e-commerce is overly optimistic. Problems like environmental pollution, financial risk due to magnified debt leverage, and security of public information have been often ignored.

The problem for the impoverished ethnic villages in Sichuan is that the products have not been integrated into the large-scale e-commerce market, or the unskilled villagers have long been 'abandoned' by the modern Internet market. Because of these information gaps, ethnic villagers in remote mountain areas lack knowledge and understanding of the modern market as well as the standards or requirements of users. In many areas, they are further constrained by poor traffic conditions and information infrastructure. Their producing factors may never be circulated in either domestic or foreign markets to make profits. Therefore, better traffic and information infrastructure investments are necessary for deeply impoverished ethnic regions. For example, the experiences and deficiencies of Taobao village in the eastern coastal area are widely known.

Furthermore, many scholars have found that proper financial policies and tools can have positive effects on economic growth and poverty alleviation. Hicks (1969) discussed the relationship between financial development and economic growth and pointed out that the financial system played a key role in the British Industrial Revolution. It greatly facilitates the flow of capital for large industrial projects. Similarly, King and Levine (1993) put financial development into an endogenous growth model and substantiated that financial development and economic growth promote each other. Greenwood and Jovanovic (1990) empirically proved that with the deepening of financial development, poor people can enter the financial market and gain high investment returns because they can be served by financial institutions and realize the equality of income distribution. Recently, Huang et al. (2016) focused on the effect of financial development on economic growth in Western China. Han et al., (2019) studied farmers' participation in inclusive finance based on a sample of 587 rural households' field survey data in the Qinba area, China. Kim (2016) investigated the effect of financial inclusion on the relationship between income inequality and economic growth. Notably, owing to the lack of credit history, it is difficult to select beneficiaries for financial inclusion, but Chao et al. (2020) developed a large-scale group decision-making model, which exhibits strong efficacy in integrating opinions when applied to China's targeted poverty-alleviation project. Also, default and bankruptcy are big problems that deter the enthusiasm and incentive for financial institutions to participate in poverty-alleviation efforts exactly because the enterprises and businesses in this area are small and incompetent. Fortunately, the bankruptcy-predicting model, particularly considering small firms in China, like Kou et al. (2021), will benefit from these institutions and soothe their concerns in this regard. Although many studies have discussed the relationship between "Internet+" tactics and productivity, few scholars have focused on the "Internet+" tactics with 
poverty alleviation in particular (Kwak et al. 2019), let alone the integration of studies on the "Internet+," financial development, economic growth, and poverty alleviation. Many Chinese scholars have qualitatively studied the effect of the "Internet+" tactics on poverty alleviation, but few have empirically examined the relationship between "Internet+" and poverty alleviation. Our study focuses on the relationship between "Internet+" and poverty alleviation in China's rural ethnic regions to guide efforts of poverty alleviation and generalize this attempt to other countries.

Until now, the hypothesis that "Internet+" tactics will enhance poverty alleviation in minority ethnic areas in Sichuan has been controversial. However, a few case studies have supported this hypothesis. In the following section, we will enrich the discussion on this issue by empirically analyzing the relationship between "Internet+" tactics and poverty alleviation.

\section{Methods}

The panel cointegration test has been widely used empirically in quantitative research on financial problems.By using the test empirically, scholars such as King and Levine (1993), Darrat (1999), and Christopoulos et al. (2004) substantiated that financial development is positively relevant to regional economic growth. By using the panel model, Zhu et al. (2011) and Giuseppe et al. (2005) recognized that technology and innovation progress can enhance regional economic growth. Comprehensively synthesizing the methods and models of the above scholars to test the impact of "Internet+" on poverty alleviation in ethnic regions of China, this article refers to the practices of Ahmed (2010) to establish a panel data model as follows:

$$
\operatorname{In} Y_{i, t}=\alpha_{0}+\alpha_{1} \operatorname{In} X_{i, t}+\sum \beta_{i} W_{i, t}+\varepsilon_{i, t}
$$

where $i$ is region, $t$ is time (year), $\alpha_{0}$ is the constant term. $Y_{i, t}$ denotes poverty alleviation indicators, and $X_{i, t}$ is the independent variable of interest (i.e., the level of "Internet+" tactics). $W_{i, t}$ is the control variable local GDP growth rate (LGDP), and $\varepsilon_{i, t}$ is the normally distributed random error (Ahmed 2010). The context of the variables is presented in Table 1.

\section{Dependent variables}

Because this study aims to assess the influence of "Internet+" tactics on poverty alleviation, it uses the per-capita income of residents (PCIR) and the per-capita income of villagers (PCIV) to measure the living standards of individuals living in that area. To measure the impact of the Internet on the government side, this article uses local government revenue (LGR) as a dependent variable and tests the relationship between "Internet+" tactics and the financial status of regional governments.

\section{Independent variable}

According to Sfenrianto et al. (2018), "Internet+" can be quantified by regional Internet users (Sfenrianto et al. 2018), which is highly related to the information and communication infrastructure rate. In addition, Fu et al. (2019) and Zhang (2008) pointed out that the proportion of Internet users among all the residents can better reflect the 
development level of "Internet+" in the same region in different periods, or in different regions in the same period. Thus, we use the proportion of Internet users among all the residents to measure CII.

\section{Control variable}

Considering that the GDP can fully influence the PCIR, PCIV and LGR, we use LGDP as a control variable.

\section{Data collection}

The panel data of the three ethnic minority prefectures of Sichuan, Aba, Ganzi, and Liangshan run from 2000 to 2018. All the data have been collected from the Annual Regional Statistical Bulletin on National Economic and Social Development, which is publicly available on the government website.

\section{Empirical findings}

\section{Estimation 1 and results}

From the results presented in Figs. 3, 4 and 5. We can see that there is a significant and positive relationship between CII and GDP in all three areas after taking the logarithm of the variables.

Next, we use a regression model that takes LGDP as the independent variable and CII as the dependent variable to test the influence of CII on LGDP. The model results are as follows.

Pooled model results:

$$
L G D P_{i, t}=460.6304+-29.5320 C I I_{i, t}+\varepsilon_{i, t} \mathrm{t}=1,2, \ldots, \mathrm{T}
$$

$(\mathrm{p}=0.0003)(\mathrm{p}=0.9772)$.

Fixed effects results:

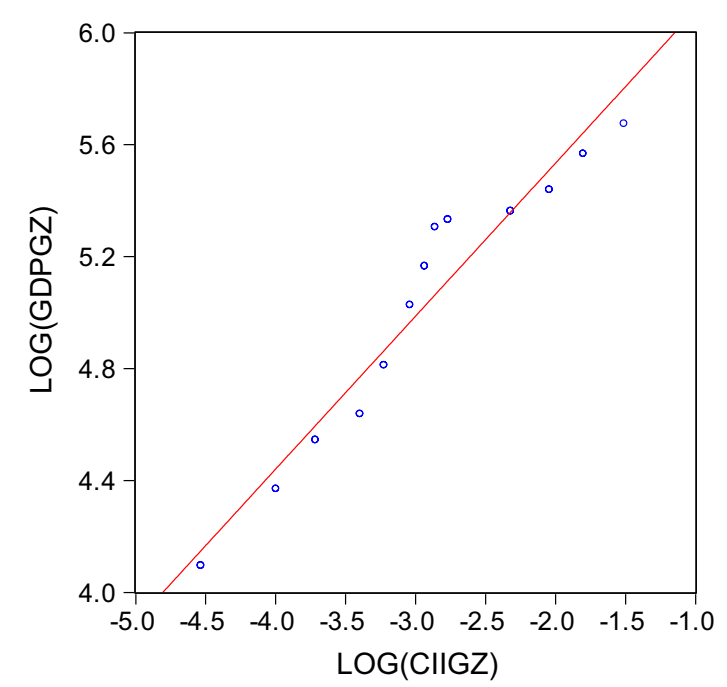

Fig. 3 Scatters of the CIl and the GDP of Ganzi 


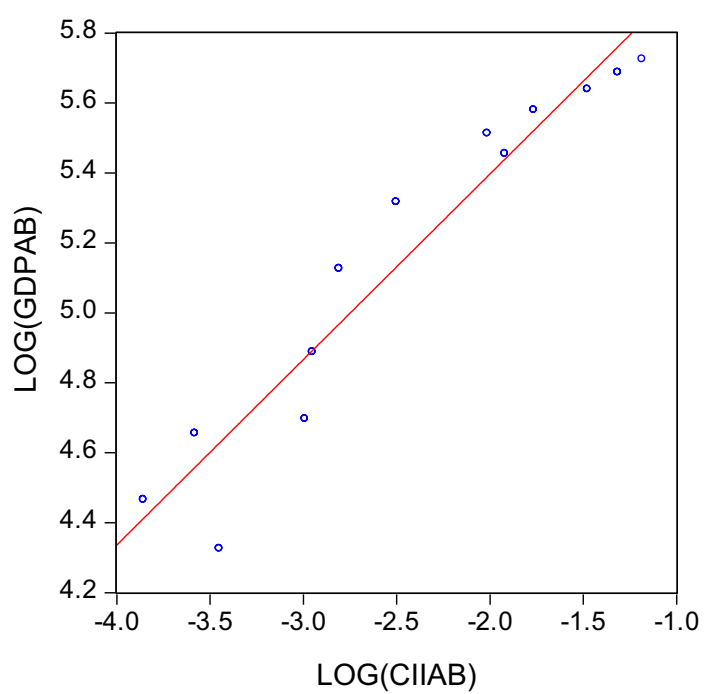

Fig. 4 Scatters of the Cll and the GDP of Aba

$$
L G D P_{i, t}=315.4503+1718.668 C I I_{i, t}+\varepsilon_{i, t} \mathrm{t}=1,2, \ldots, \mathrm{T}
$$

$(\mathrm{P}=0.00)(\mathrm{P}=0.002)$.

Random effects results:

$$
L G D P_{i, t}=318.1920+1685.654 C I I_{i, t}+\varepsilon_{i, t} \mathrm{t}=1,2, \ldots, \mathrm{T}
$$

$(\mathrm{p}=0.2589)(\mathrm{p}=0.0023)$.

From the results, we see that 1 unit of growth in the CII improves 1718.668 of the LGDP. This finding indicates that information infrastructure can improve local GDP; thus, from a macro perspective, CII plays an important role in local GDP growth in Aba, Ganzi, and Liangshan.

\section{Estimation 2 and results}

Next, using a pooled model, the fixed-effects regression model, and the random-effects regression model, we estimate the effects of CII by making LGDP a control variable.

Table 2 shows that all six regression results are acceptable and that the fixed effects of the regression model are more reliable because the adjusted-R2 at (2.1) is higher than that at (1.1), (3.1). The adjusted-R2 at (2.2) is higher than (1.2), (3.2). The constants in (1.2), (3.2) are significant at the $1 \%$ level. The control variable, LGDP, has a positive effect on the revenue of individuals in (1.1), (1.2), (3.1), (3.2), which is consistent with the empirical research.

Therefore, we conclude that CII (1) influences the revenues of both township residents and rural villagers, and (2) plays a significant role in promoting the revenue of individuals within that area. Additionally, (3) in the ethnic regions of Sichuan Province, the stimulation of the "Internet+" tactics works better in towns than in rural villages because the income growth rate of the township residents $(7.4813)$ is higher than that of the rural villagers (3.8728). 


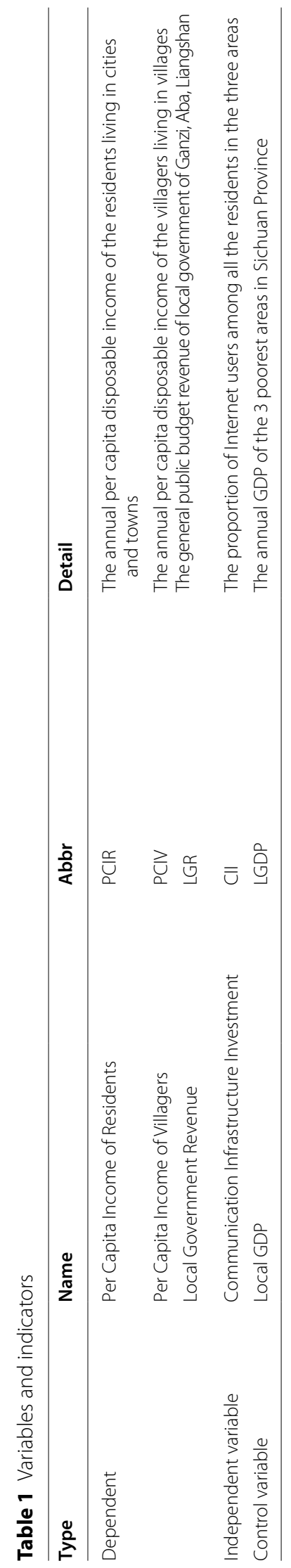


Table 2 Estimation of the relationship between "Internet+" tactics and poverty indicators

\begin{tabular}{lllllll}
\hline & PCIR & PCIV & PCIR & PCIV & PCIR & PCIV \\
\hline CII & $(1.1)$ & $(1.2)$ & $(2.1)$ & $(2.2)$ & $(3.1)$ & $(3.2)$ \\
& $8.4548^{* * *}$ & $3.9889^{* * *}$ & $7.4813^{* * *}$ & $3.8728^{* * *}$ & $8.4548^{* * *}$ & $3.9888^{* * *}$ \\
& $(0.6777)$ & $(0.2073)$ & $0.6328)$ & $(0.2299)$ & $(0.5079)$ & $(0.1846)$ \\
LGDP & $0.0005^{* * *}$ & $0.0004^{* * *}$ & $0.0012^{* * *}$ & $0.0005^{* * *}$ & $0.0005^{* * *}$ & $0.0004^{* * *}$ \\
& $(0.0001)$ & $(0.0000)$ & $(0.0002)$ & $(0.0001)$ & $(0.0001)$ & $(0.0000)$ \\
Constant & $1.0160^{* * *}$ & $0.1250^{* * *}$ & $0.7839^{* * *}$ & $0.0801^{* * *}$ & $1.0160^{* * *}$ & $0.1250^{* * *}$ \\
& $(0.0901)$ & $(0.0276)$ & $(0.0821)$ & $(0.0298)$ & $(0.0676)$ & $(0.0246)$ \\
Adjusted-R2 & 0.8336 & 0.9314 & 0.9118 & 0.9486 & 0.8336 & 0.9314 \\
F-statistic & 90.2041 & 244.3164 & 87.8219 & 156.9828 & 90.2041 & 244.3164 \\
Prob (F-statistic) & 0.0000 & 0.0000 & 0.0000 & 0.0000 & 0.0000 & 0.0000 \\
Model & Pooled model & & Fixed effects & & Random effects & \\
\hline
\end{tabular}

${ }^{*} p<0.05 ;{ }^{* *} p<0.01 ;{ }^{* * *} p<0.001$

Table 3 Estimation results of the relationship between "Internet+" tactics and LGR

\begin{tabular}{llll}
\hline & LGR & & \\
\cline { 2 - 4 } & $\mathbf{( 1 . 1 )}$ & $\mathbf{( 1 . 2 )}$ & $\mathbf{( 1 . 3 )}$ \\
\hline CII & $32.1492^{* *}$ & 0.6714 & $32.1492^{* * *}$ \\
LGDP & $(13.1255)$ & $(11.2323)$ & $(9.0145)$ \\
& $0.0847^{* * *}$ & $0.1021^{* * *}$ & $0.0847^{* * *}$ \\
Constant & $(0.0021)$ & $(0.0032)$ & $(0.0014)$ \\
& 0.3914 & $-4.9541^{* * *}$ & $0.3914^{* * *}$ \\
Adjusted-R2 & $(1.7459)$ & $(1.4567)$ & $(1.1991)$ \\
F-statistic & 0.9772 & 0.9893 & 0.9784 \\
Prob (F-statistic) & 815.6414 & 875.1880 & 815.6414 \\
Model & 0.0000 & 0.0000 & 0.0000 \\
\hline
\end{tabular}

${ }^{*} p<0.05 ;{ }^{* *} p<0.01 ;{ }^{* * *} p<0.001$

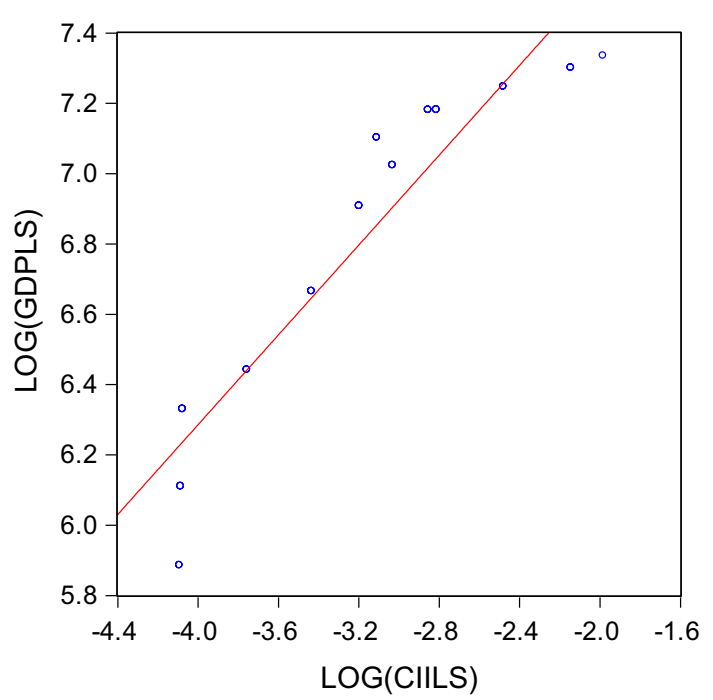

Fig. 5 Scatters of the Cll and the GDP of Liangshan 


\section{Estimation 3 and results}

Further, we want to assess the effects of the "Internet+" tactics on LGR. With LGR as the dependent variable, the independent variable and control variable remain the same as before.

Table 3 indicates that two of the regression results are optimistic. The parameters estimated from the pooled model and the random effects model are identical and significant, but the coefficient estimated from the fixed effects regression model is not. From the result, we conclude that concerning (1.2) the fixed effects, the parameter of CII is negative and can only be trusted at the $5 \%$ significance level. Thus, the results of the pooled model and random effects model are preferred.

The conclusions are that CII (1) influences government revenue positively and (2) plays a significant role in improving the revenue of the local government.

"Internet+" tactics is one of the platform economies that can dramatically enlarge the scale of productivity and sales. The most direct economic benefits are scale and the network effect. E-commerce platforms such as Amazon, Alibaba, eBay, and Jingdong, through online and offline integration, have reduced the information asymmetry between producers and consumers and intermediate circulation. Rural organizations have greatly increased the scale of sales through the Internet platforms and have received timely feedback from consumers, driving a significant increase in the sales of specialty agricultural products. Finally, it increases the income level of farmers and governments in China's poor ethnic areas.

\section{Robustness test}

We conduct a robustness test from the following two aspects. (1) We test whether the "Internet+" tactics and poverty-alleviation indicators are causal. While "Internet+" tactics increase the local revenues and GDP, the increasing residential and government revenues as well as GDP growth can also promote the indicator we use to measure the "Internet+" tactics, and vice versa. Referring to Xie, Yuan, and Huang's method (Xie et al. 2017), the lag of $I n C I I$ is used as the core explanatory variable. The logic is that the current poverty indicator is the counterpart of the first lag in InCII. The effect of the lagged InCII on the current poverty indicators does not change and indicates that "Internet+" tactics are the main cause of the two-way causality. The results show that the regression coefficient and the significance level of explanatory variables and control variables have not changed substantially, indicating that the endogeneity problem is not a concern for the robustness of our conclusion. (2) Poverty alleviation is affected by a series of factors, such as the infrastructure development level, urbanization level, and market prosperity. To avoid endogeneity caused by missing variables, we added urbanization, infrastructure, and the market as control variables in the estimation. The conclusions are consistent with the aforementioned basic regressions.

\section{VAR test}

The VAR model is widely used to solve the problem of data-based assessment and prediction. Filho and Valk (2020) built the dynamic VAR model-based control charts for batch process monitoring. Zhang and Lin (2019) focused on whether the VAR model 
outperforms other models for asset allocation in the commodity market under a complex investment environment. Thus, we use the VAR model to assess the impulse of CII to the LGDP, LGR, PCIR, and PCIV to further substantiate the aforementioned results. This part uses the data from the Liang Shan District.

\section{Estimation 4 and Results}

To test the relation between CII and GDP in Liangshan district, the VAR model is used as follows:

$$
Y_{t}=\alpha+\sum_{i=0}^{n} \beta_{i} Y_{t-i}+\sum_{i=0}^{n} \gamma_{i} X_{t-i}+\mu
$$

It sets GDP as $Y_{t}, \mathrm{CII}$ as $X_{t}, \mathrm{t}$ as the time indicator, and $\mathrm{i}$ as the lag order. Before performing the regression, we test the stationarity of the data. Figure 6 shows that it passes the $A R$ roots test.

The VAR equations are:

$$
\begin{aligned}
\log \mathrm{GDP}= & 1.0322+0.1318 \log \mathrm{CII}(-1)+-0.1517 \log \mathrm{CII}(-2) \\
& +0.8602 \log \mathrm{DPP}(-1)-0.0077 \log \mathrm{DPP}(-2) \\
\log \mathrm{CII}= & -1.0694+1.0331 \log \mathrm{CII}(-1)-0.2074 \log \mathrm{CII}(-2) \\
& \pm-0.7111 \log \mathrm{GDP}(-1)+0.8242 \log \mathrm{GDP}(-2)
\end{aligned}
$$

\section{Impulse response}

Next, we use the impulse response of GDP to CII and the result shows that the response of GDP to CII's impulse in Liang Shan District. When there is an impulse of CII, the GDP responses are subtle during the first two years, which indicates that CII cannot influence the GDP immediately. However, the response increases sharply starting in the

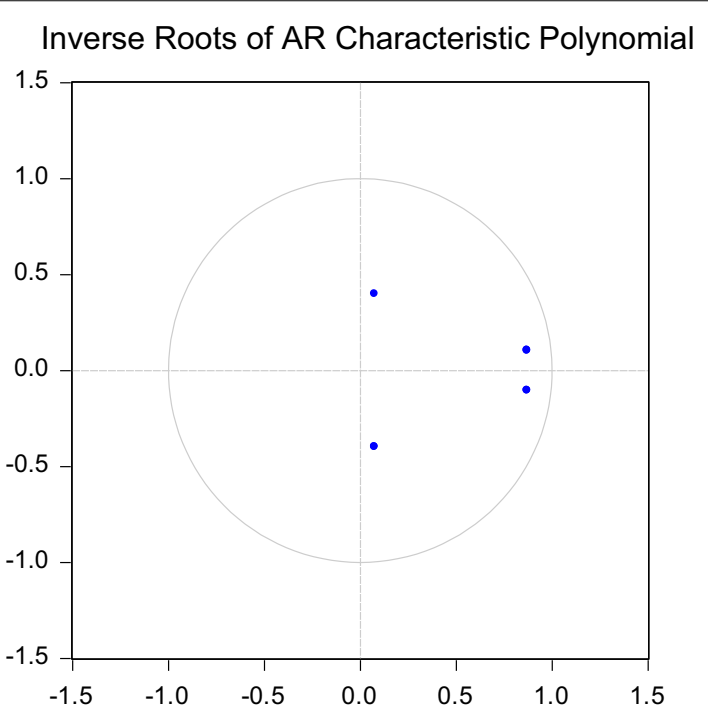

Fig. 6 AR roots test 


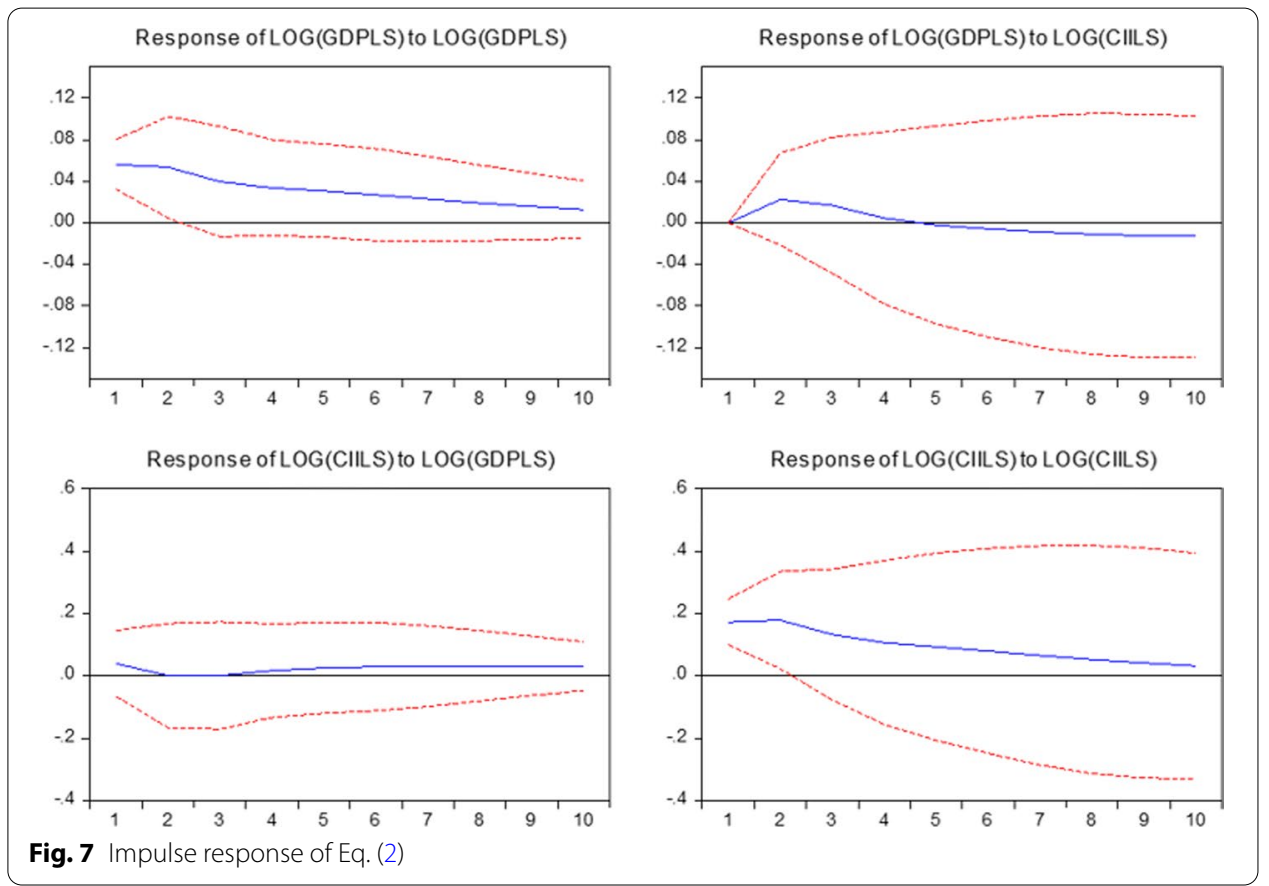

third year and reaches the peak in the sixth year. Subsequently, the response begins to weaken, and the variance shows convergence, as shown in Fig. 7.

It indicates that strengthening CII can affect local GDP immediately with other factors such as transportation infrastructure investment, urbanization, and export. During years 1-4, strengthening CII can boost e-commerce market growth and stimulate, for example, "Internet+" tourism, agriculture, and e-finance. Thus, it will have an obvious impulse on local GDP. After 4 years, the impact of CII on GDP is almost zero.

\section{Estimation 5 and results}

To assess the correlation among CII, LGR, and PCIR or PCIV in Liang Shan District, the VAR model is specified as follows:

$$
Y_{t}=\alpha+\sum_{i=0}^{n} \beta_{i} Y_{t-i}+\sum_{i=0}^{n} \gamma_{i} X_{t-i}+\sum_{i=0}^{n} \theta_{i} M_{t-i}+\mu
$$

It again sets the GDP as $Y_{t}$. However, to distinguish the difference between PCIR and PCIV, the model sets PCIR as $X_{t}$ and LGR as $M_{t}$. Moreover, $t$ is the time series, and $i$ is the lag order. We calculate the VAR equations as follows:

$$
\begin{aligned}
\operatorname{logLCR}= & 0.1257+0.0106 \log \mathrm{CII}(-1)+0.0629 \log \mathrm{CII}(-2)+1.6846 \operatorname{logLGR}(-1) \\
& -0.7187 \operatorname{logLGR}(-2)-0.8528 \log \mathrm{PCIR}(-1)+0.7028 \operatorname{logPCIR}(-2) \\
\operatorname{logPCIR}= & -0.3909+0.0187 \log \mathrm{CII}(-1)+0.0139 \log \mathrm{CII}(-2)+0.2667 \operatorname{logLGR}(-1) \\
& -0.1343 \operatorname{logLGR}(-2)+0.5459 \log \mathrm{PCIR}(-1)+0.1397 \log \mathrm{PCIR}(-2)
\end{aligned}
$$




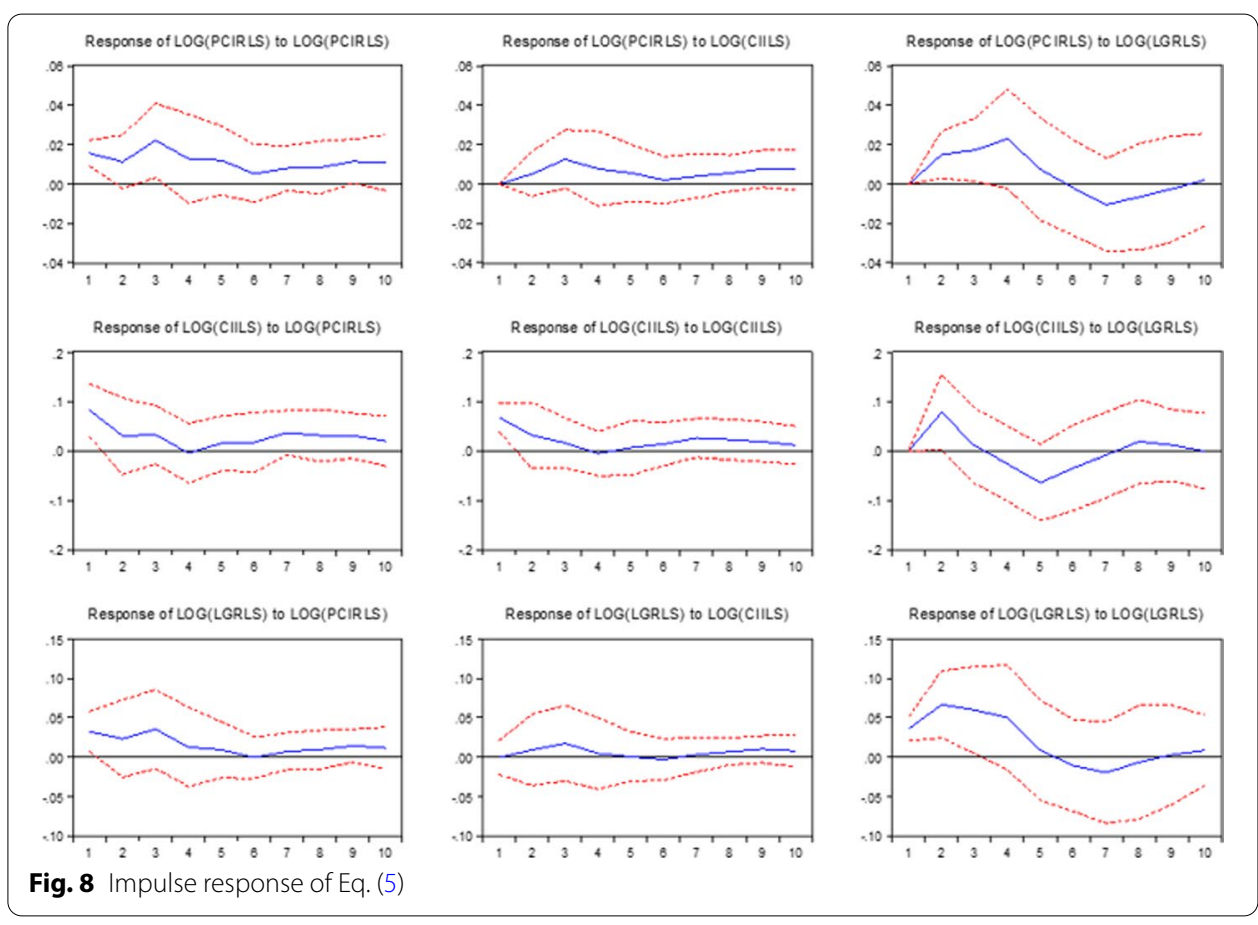

$$
\begin{aligned}
\log \mathrm{CII}= & 5.3009+0.4733 \log \mathrm{CII}(-1)-0.3831 \log \mathrm{CII}(-2)+0.2290 \operatorname{logLGR}(-1) \\
& -1.2494 \log \mathrm{LGR}(-2)+1.6908 \log \mathrm{PCIR}(-1)+1.7414 \log \mathrm{PCIR}(-2)
\end{aligned}
$$

\section{Impulse response}

The next step is to make an impulse response of LGR to CII and PCIR to CII separately.

Figure 8 is the impulse response of Eq. (5), which encompasses 9 graphs. The second graph in the first row shows that the response of PCIR changes smoothly with the time and peaks in year 3 . The second graph in the third row also shows that the response of LGR changes smoothly with time and peaks in year 3 . This finding indicates that the impulse of CII influences the PCIR and LGR immediately and almost simultaneously.

\section{Estimation 6 and results}

To assess the different impulses of CII to PCIR and PCIV, the model sets GDP as $Y_{t}$, PCIV as $X_{t}$, and PCIR as $W_{t}$. In the same fashion, $t$ is the time series, and $i$ the lag order.

$$
Y_{t}=\alpha+\sum_{i=0}^{n} \beta_{i} Y_{t-i}+\sum_{i=0}^{n} \gamma_{i} X_{t-i}+\sum_{i-0}^{n} \theta_{i} W_{t-i}+\mu .
$$

Because we already compared the different effects of CII to PCIR and PCIV, now, we only need to compare the different impulse response of PCIR and PCIV to CII. From Fig. 8, we observe that the impulse of CII influences the PCIV sharply. Moreover, the 


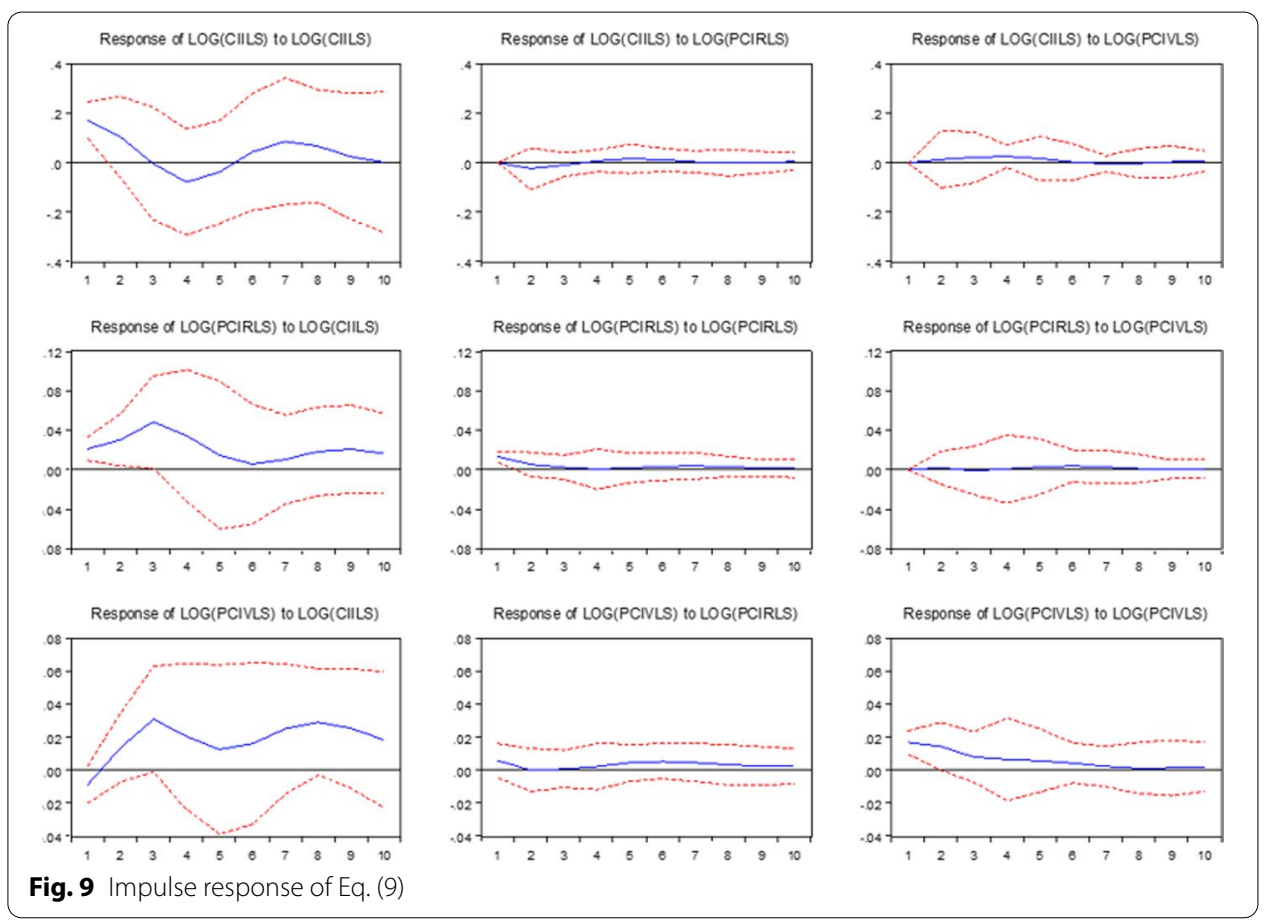

response of PCIV increases with time. The finding indicates that the CII has a quick and lasting effect on the improvement of the rural villagers' income. Considering that the ethnic rural villagers are poorer than the township residents, communication infrastructure can have a better effect on rural village residents than on township residents.

Figure 9 shows the impulse response of Eq. (9), from which we found that CII can improve both PCIV and PCIR immediately, and the effect is lasting; however, from years 2 to 3, the impact of CII is larger on PCIR.

These results indicate that in China's rural ethnic regions, especially in Sichuan Province, because of the poor geographic condition, the scattered market, and inefficient but high-cost logistics, increasing local villagers' revenue by traditional means is difficult. However, "Internet+" tactics can integrate the rural families into the modern market and greatly reduce the cost of information acquisition and logistics; thus, the stimulation effect is strong and direct in enhancing poor rural families' revenues.

\section{Conclusions and policy implications}

Based on panel and VAR analysis, the empirical results significantly substantiate the hypothesis that "Internet+" tactics may have a positive effect on poverty alleviation in China's ethnic poor rural regions. Similar to many scholars' perspectives, "Internet+" tactics offer a reliable means to alleviate rural areas' poverty because they can cultivate new business models, new technology, and even new markets. To further substantiate the aforementioned statement, we use data from the Liangshan, Aba, and Ganzi ethnic regions from 2000 to 2018 to empirically verify our hypothesis. The conclusions and policy context are as follows: 
1. For the sampling duration, "Internet+" tactics can have a positive effect on local GDP and LGR. Through a VAR analysis, in the first six years, the margins of the impulse of the "Internet + " tactics expand but tend to converge after the first six years. Thus, the "Internet + " tactics alone do not solve the ethnic regions' poverty problems. The local government must fully use the advantages of the "Internet+" tactics to boost new industries and new growth motives. Comprehensive actions such as developing infrastructure (e.g., highway, railways, and high-speed networks, and stable power grids) and building innovative industrial and agricultural platforms are necessary for the "Internet+" tactics to work their magic and improve ethnic rural economies.

2. From the panel and VAR analysis, we observe that "Internet+" tactics have a very positive and persistent effect on ethnic rural families' income, and the margin has been enlarged over time. We assert that training ethnic rural individuals to master the Internet and relevant "Internet+" apps as production and sales tools is essential. It is very significant for the ethnic local government to develop new industries such as "Internet+" tourism, "Internet+" special agriculture, and "Internet+" sports. Additionally, the central and provincial government must strengthen CII and promote the rural informatization process consistently to facilitate ethnic rural use of "Internet+" to transform their lives.

3. We use the model "Government subsidy + Market operation" to support the rural "Internet+" platform. The aforementioned analysis demonstrates the significance of the "Internet+" platform to the ethnic rural areas in Sichuan. One significant problem is that the "Internet+" platform has obvious external characteristics, and businesses are reluctant to invest capital to enter and take the unknown market risk in the initial phase. Thus, policies should ensure that provincial and local governments implement subsidies to encourage entrepreneurs to set up the "Internet+" platform in rural ethnic regions in a manner that fulfills certain standards. Once the local "Internet+" platforms have highly been integrated into the market, the government should suspend the subsidies to avoid the subsidy's malfunction on the development of the market. Additionally, the "Internet+" platform should be fully open and approachable to every rural household. Quality oversight is required to ensure the market will not quickly degenerate.

4. According to the above conclusions, first, the ethnic impoverished regions should highlight the special role of e-commerce in poverty alleviation and further rural revitalization and should aim to build up leading industrial ecological circles like the big data industry, agricultural products processing, and the tourism and health industry, which will equip those industries with network support and digital and intelligent transformation. Second, per the developmental logic of the industrial chains, ethnic impoverished regions should recruit projects by "building, converging, supplementing, strengthening, extending, and expanding" industrial chains to form the production capacity needed to meet market standards. Third, ethnic impoverished regions should make an effort to promote the concentration of high-quality producing elements in local industrial ecological circles by providing policy and carrier support, as well as highly efficient government services to form the scale effect of superior local industries. 
5. For sustainable development in rural ethnic areas, the local government should draw a clear ecological red line for "Internet+" industries. First, to protect local geological brands and intellectual property and avoid the effect of "bad money driving out good money," local regulatory authorities should crack down on counterfeit products that cannot meet market standards and infringe on the intellectual property rights of other suppliers. Second, to protect ecologically vulnerable areas in ethnic impoverished areas in Sichuan, the local government should plan and set the bottom line of industrial expansion regarding over-exploration of natural resources or uncontrolled gas emissions from the over-breeding of animals.

6. Internet financing tools with credit-checking systems could be widely applied to boost the economy in ethnic rural areas with severe poverty problems. In general, Internet financing lowers the barrier for remote and small businesses to raise funds and reduce their financial pressure. The integration of e-commerce and Internet financing will improve market efficiency. To manage the credit risk associated with Internet financing, a credit-checking system for individual and small businesses should be established. The information integration from e-commerce and logistics will also contribute to the accuracy and efficiency of the credit-checking system. A mature credit-checking system will help establish a stable "Internet financing-ecommerce" eco-system.

\section{Acknowledgements}

The authors acknowledge the editors and anonymous reviewers for providing the constructive comments and suggestions that substantially improved the quality of the study.

\section{Authors' contributions}

XY: Conceptualization, Supervision, Model Building, Writing original draft. ZM: Data Arrangement, Writing original draft. XY: Writing, Model Building, Reviewing and Editing. YW: Methodology, Software. XH: Formal analysis, Writing-review and editing. All authors read and approved the final manuscript.

\section{Funding}

This research has been supported by the National Social Science Foundation of China (Grant No. 19BJL126), and the National Natural Science Foundation of China (Grant No. 71903139). It has been also supported by the Humanities and Social Sciences Foundation of the Ministry of Education of China (Grant No. 16YJC630089), Annual projects of the National Ethnic Affairs Commission of the People's Republic of China (Grant No. 2020-GMC-032) and the Basic Scientific Research Service Fee Project of Central Universities of Sichuan University (Grant Nos. 2020 CXQ07 and skbsh2019-36).

\section{Availability of data and materials}

The data-sets used during the current study are available from the corresponding author on reasonable request.

\section{Declarations}

\section{Competing interests}

The authors declare that they have no competing interests.

\section{Author details}

${ }^{1}$ Institute of South Asia Studies, Sichuan University, Chengdu 611130, People's Republic of China. ${ }^{2}$ School of Business, Sichuan University, Chengdu 611130, People's Republic of China. ${ }^{3}$ School of Economics, Sichuan University, Chengdu 611130, People's Republic of China. ${ }^{4}$ School of Securities and Futures, Southwest University of Finance and Economics, Chengdu 611130, People's Republic of China.

Received: 19 August 2020 Accepted: 9 March 2021

Published online: 27 April 2021

\section{References}

Acemoglu D, Dorn D, Hanson GH, Price B (2014) Return of the Solow paradox? IT, productivity, and employment in US manufacturing. Am Econ Rev 104(5):394-399 
Ahmed EM (2010) Human capital and ICT per capital contribution to East Asian productivity growth. Int Regional Sci Rev 85(1/2):40-55

Béné C, Arthur R, Norbury H, Allison EH, Beveridge M, Bush S et al (2016) Contribution of fisheries and aquaculture to food security and poverty reduction: assessing the current evidence. World Dev 79:177-196

Chandio AA, Jiang Y, Rehman A (2018) Credit margin of investment in the agricultural sector and credit fungibility: the case of smallholders of district Shikarpur, Sindh, Pakistan. Financ Innov 4:27

Chao X, Kou G, Peng Y, Viedma EH (2020) Large-scale group decision-making with non-cooperative behaviors and heterogeneous preferences: an application in financial inclusion. Eur J Oper Res. https://doi.org/10.1016/j.ejor.2020. 05.047

Christopoulos DK, Tsionas EG (2004) Financial development and economic growth: evidence from panel unit root and cointegration tests. J Dev Econ 73(1):55-74

Copestake J, Dawson P, Fanning JP, McKay A, Wright-Revolledo K (2005) Monitoring the diversity of the poverty outreach and impact of microfinance: a comparison of methods using data from Peru. Dev Policy Rev 23(6):703-723

Cui M, Pan SL, Newell S, Cui L (2017) Tactics, resource orchestration and e-commerce enabled social innovation in Rural China. J Strategic Inf Syst 26(1):3-21

Darrat A (1999) Are financial deepening and economics causally related? Another look at the evidence. Int Econ J 13(3):19-35

Filho DM, Valk M (2020) Dynamic VAR model-based control charts for batch process monitoring. Eur J Oper Res 285(1):296-305

Fosu AK (2017) Growth, inequality, and poverty alleviation in developing countries: recent global evidence. Res Econ 71(2):306-336

Fu J, Liu Y, Chen R, Yu X, Tang W (2019) Trade openness, internet finance development and banking sector development in china. Econ Model 91:670-678

Gong B (2018) The impact of public expenditure and international trade on agricultural productivity in China. Emerg Mark Finance Trade 54(15):3438-3453

Giuseppe A, Basile R, Piras G (2005) Using spatial panel data in modeling regional growth and convergence. ISAE working paper, No 55

Han J, Wang J, Ma X (2019) Effects of farmers' participation in inclusive finance on their vulnerability to poverty: evidence from Qinba poverty-stricken area in China. Emerg Mark Finance Trade 55(5):998-1013

Hicks J (1969) A theory of economic history. Clarendon Press, Oxford, pp 102-135

Huang Y, Liu Y, Wu H (2016) The finance-growth nexus and poverty reduction in Western China. Emerg Mark Finance Trade 52(2):513-521

Greenwood J, Jovanovic B (1990) Financial development, growth, and the distribution of income. J Polit Econ 98(5):1076-1107

Kennedy E, Guzmán F (2016) Co-creation of brand identities: consumer and industry influence and motivations. J Consum Mark 33(5):313-323

Kim JH (2016) A study on the effect of financial inclusion on the relationship between income inequality and economic growth. Emerg Mark Finance Trade 52(2):498-512

King RG, Levine R (1993) Finance and growth: Schumpeter might be right. Q J Econ 108(3):717-737

Kolk A (2016) The social responsibility of international business: from ethics and the environment to CSR and sustainable development. J World Bus 51(1):23-34

Kou G, Xu Y, Peng Y, Chang K, Kou S (2021) Bankruptcy prediction for SMEs using transactional data and two-stage multiobjective feature selection. Decis Support Syst. https://doi.org/10.1016/j.dss.2020.113429

Kwak J, Zhang Y, Yu J (2019) Legitimacy building and e-commerce platform development in China: the experience of Alibaba. Technol Forecast Soc Change 139:115-124

Li L (2018) China's manufacturing locus in 2025: With a comparison of "Made-in-China 2025" and "Industry 4.0."Technol Forecast Soc Change 135:66-74

Li L, Du K, Zhang W, Mao JY (2019) Poverty alleviation through government-led e-commerce development in rural China: An activity theory perspective. Inf Syst J 29(4):914-952

Lin Z, Whinston AB, Fan S (2015) Harnessing Internet finance with innovative cyber credit management. Financ Innov 1(5):1-24

Lund-Thomsen P, Lindgreen A, Vanhamme J (2016) Industrial clusters and corporate social responsibility in developing countries: what we know, what we do not know, and what we need to know. J Bus Ethics 133(1):9-24

Olayungbo DO, Quadri A (2019) Remittances, financial development and economic growth in sub-Saharan African countries: evidence from a PMG-ARDL approach. Financ Innov 5(1):1-25

Page J, Shimeles A (2015) Aid, employment and poverty alleviation in Africa. Afr Dev Rev 27(S1):17-30

Rosenstein-Rodan PN (1943) Problems of industrialisation of eastern and south-eastern Europe. Econ J (Lond) 53(210/211):202-211

Sfenrianto S, Wijaya T, Wang G (2018) Assessing the buyer trust and satisfaction factors in the E-marketplace. J Theor Appl Electron Commer Res 13(2):43-57

Shen F, Zhao X, Kou G (2020) Three-stage reject inference learning framework for credit scoring using unsupervised transfer learning and three-way decision theory. Decis Support Syst. https://doi.org/10.1016/j.dss.2020.113366

Solow RM (1987) We'd Bertter watch out. New York Times Book Review 12-01(36)

Tang WC, Zhu J (2020) Informality and rural industry: rethinking the impacts of e-commerce on rural development in china. J Rural Stud 75:20-29

Vakulenko Y, Shams P, Hellström D, Hjort K (2019) Service innovation in e-commerce last mile delivery: mapping the e-customer journey. J Bus Res 101:461-468

Wang H, Wen T, Han J (2019) Can government financial inflows effectively reduce poverty in poverty-stricken areas? Evidence from China. Emerg Mark Finance Trade 1-13

Xie RH, Yuan YJ, Huang JJ (2017) Different types of environmental regulations and heterogeneous influence on "green" productivity: evidence from China. Ecol Econ 132:104-112 
Yan T, Qian WY (2004) Environmental migration and sustainable development in the upper reaches of the Yangtze River. Popul Environ 25(6):613-636

Zaefarian R, Tasavori M, Ghauri PN (2015) A corporate social entrepreneurship approach to market-based poverty reduction. Emerg Mark Finance Trade 51(2):320-334

Zhang Y, Lin J (2019) Can the VAR model outperform MRS model for asset allocation in commodity market under different risk preferences of investors. Int Rev Financ Anal. https://doi.org/10.1016/j.irfa.2019.101395

Zheng S, Duan Y, Ward MR (2019) The effect of broadband internet on divorce in China. Technol Forecast Soc Change 139:99-114

Zhu C, Chen L (2018) An analysis of the development of China's commercial banks under the structural reform of the supply side. J Acco Bus Finance Resh 4(1):1-8

Zhu D, Zeng D, Zhou Q (2011) Regional technical innovation suitability and economic growth. Int J Innov Sustain Dev 6(4):441-452

\section{Publisher's Note}

Springer Nature remains neutral with regard to jurisdictional claims in published maps and institutional affiliations.

Submit your manuscript to a SpringerOpen ${ }^{\circ}$ journal and benefit from:

- Convenient online submission

- Rigorous peer review

- Open access: articles freely available online

- High visibility within the field

- Retaining the copyright to your article

Submit your next manuscript at $>$ springeropen.com 